\title{
Importance of Electrical Circuits Protection Devices: A Survey Study
}

\author{
Atef S. Al Mashakbeh \\ Tafila Technical University \\ P.O.Box 179, Tafila 66110, JO
}

\begin{abstract}
Electric circuit protection devices are known as the protection devices for different electrical circuits. These devices are used for reducing the overall ratio of hazardous occurrence in the electric circuit. The research of importance of electrical circuit protection devices in industries is undertaken through the primary quantitative method by taking the 70 respondents in the survey analysis. Hazardous conditions occur due to lack of availability of electrical circuit protection devices. Therefore, the utilization of these devices is proved as beneficial for industries.
\end{abstract}

\section{Keywords}

Circuit Protection, Fuse, Breaker, Sampling, Hazardous Conditions

\section{INTRODUCTION}

Electrical circuit protection is referred as the protection of different electrical circuits with the help of intentional installation of the weak link. The protection of electrical circuits is done through different protection devices such as; fuse or circuit breakers. The complexity and importance of electrical equipment are continuously increasing within the commercial, residential and industrial installation. However, the protection equipment is also deemed critical for different system operations in industries [1]. Electrical protection devices also have the large value in industries context as any fault or misleading of current can cause huge loss for industries in terms of safety and productivity. Additionally, these devices are proven as the essential hand in different industries as these devices provide safety and protection from facing any electrical hazard.

The importance and need of circuit protection are continuously increasing as there are various cases in which industries have faced the huge amount of loss due to the electrical fault. Every electrical circuit has the large value as it helps industries and individual with numerous electrical facilities [1]. The word current has its value as various people get furious but this current provides people the required electricity through which numerous tasks can be performed. The protection circuits help current to follow the intended path and to overcome any electrical hazards. Moreover, the very small problems within electrical circuits can cause large problems for industries if these problems do not get corrected or detected on time [2]. It is known to all that electrical circuits protection has the large value in different operations of industries. Therefore, the research will try to identify the impact of electrical circuit protection devices in the context of industries. This section of introduction will cover the detailed concepts of electrical circuit protection devices and the overall utilization of these devices within different industries. The section of introduction also covers the aim of undertaking the research and the objectives and questions of research that will help in fulfilling the aim of this research.

\subsection{Aim and Objectives of this Study}

This research is undertaken with the aim of evaluating and analyzing the impact of electrical circuit protection devices within different industries. Furthermore, the research will also evaluate the designing of protection system for different electrical circuits. Following are the objectives that will help research in achieving the aim of this study.

1) To identify the different electrical circuit protection devices and their utilization in industries.

2) To evaluate the importance of electrical circuit protection devices in industrial context for protecting the devices.

3) To find out the different problems while designing the protection system for the electrical circuits.

\subsection{Background of the Study}

Electricity provides people various benefits as it has become the most important asset for a human to survive in this world. However, electricity has also become the reason of death for many as the different fault of electricity or wrong connection cause death for people. Gan, (2014) mentioned in his study that there are various advantages of electricity, but it is necessary for people to take the proper protection of different electrical circuits [1]. Furthermore, the different cases of electrical death show that electrical current should be kept under high control regularly for the security of people and equipment. Dougherty (2015) stated that electrical devices have achieved the high value in people's lives as these devices are used for the safety of people in different electrical circuits that are used at residential, commercial or industrial areas [2].

Gan, (2014) also claimed that the devices of electric circuit protection are developed for protecting people and different electrical circuits from the high voltages and current outside their normal ranges [1]. It is necessary to have overcurrent protection for preventing the small and controllable program from getting the much large issue. Electrical protection devices are used in various industries as these devices provide people the required protection while working with different and high voltage electrical circuits. There is other equipment that is also used by the electrical engineers while working with high voltage electrical circuits, but the devices like circuit breakers or fuse have high efficiency in restricting current and in saving people from any danger. Kageyama, Takeda, Murano, and Itagaki, (2015) also mentioned that the potential damaging overcurrent is also a large or regular raised issue as this issue can arise from component failure, accidental shorting or excessive voltage of circuits [3]. Expósito et al. (2016) identified that the failure of different electrical circuits is due to the increased rate of the heat of different components within circuits [4]. The excessive amount of heat level of components within electrical circuits may result in fire [3]. Therefore, these electrical circuit 
protection devices also help industries and individuals in preventing the production of excessive current from damaging heat. However, it can be stated that both electrical and electronic devices do not have the capability of distinguishing the normal load and overloads as different circuits draw more current due to the increased of current which at last result in the burned equipment due to lack of circuit protection $[5,6]$.

\subsection{Research Questions}

This research study covers different questions that will be covered in this research for analyzing the influence of electrical protection devices in industrial context.

1) What are the different electrical circuit protection devices that are used for protecting the electrical devices?

2) How can industries design the protection system with high efficiency?

3) Why are these devices become necessary for different residential and industrial operations?

\section{LITERATURE REVIEW}

\subsection{Circuit Conditions Requiring Protection Devices}

There are various conditions within industrial operations in which different electrical circuit protection devices are used. Franks, Williams, and Cole, (2014) claimed that various conditions can be occurred while using the electrical and electronic devices [5]. However, it can be stated that changes in the working of the circuit can cause problems for the circuit and for the people who work near the circuits. Padilla et al. (2014) stated that it is necessary to have electrical circuit protection devices for securing and protecting the electrical circuits [6]. However, the conditions in which these devices are used are excessive current, excessive heat, and direct shorts.

\subsubsection{Excessive Current}

The excessive current is referred as the increase of current within electrical circuit due to any fault in the circuit. Circuit current can easily increase without the direct short within the circuit. It can be stated that the change in the value of any resistor, inductor, and capacitor cause the change in the value of circuit impedance. Mitolo and Montazemi, (2014) stated that excessive current is the most identified situation in which electric circuit protection devices are required to be used as any resistor of the circuit decreased its ohmic value, the overall resistance of the circuit gets low [7]. Furthermore, the change in the capacitor or rise of dielectric leakage also causes the decrease in the resistance of the capacitor. However, Roscoe et al. (2015) identified in the study of Padilla et al. (2016) that any change within inductor, capacitor or resistor of the electric circuit results in the raise of the current of the circuit [6]. Furthermore, any short at the winding of the inductor can also decrease the inductive reactance of the circuit. The electrical circuits in which wiring and designing of components are made with normal circuit current can also cause overheating due to the increment of current. Therefore, these overall conditions can be the reason for excessive heat

\subsubsection{Direct Short}

Direct Short is one of the most and serious troubles that are identified in the different electric circuit. Direct short is referred as contact between the full system voltage with ground or return side of the circuit. Neitzel, (2016) mentioned that direct short cause high effects on the circuit and it is also known as the Short Circuit [8]. However, the path on which high voltage and ground get into contact has the minimum resistance which helps current to flow through that path. Direct short cause large problems for industries as there are various cases of death due to direct short in the high electric circuit. It can be stated that maximum current will flow when there is low resistance in the circuit. For example, if the wires of battery came into contact with each other while running of the motor there will be high chances of producing direct short in the circuit. Both wires are the symbol of the forward and backward path, and as the result of this contact the motor stop running and the motor get burned or can have the explosion [8]. Xin, Xiong, and Li, (2014) mentioned that the most of the wires that are used in the electrical circuits are smaller and have the very low current capacity [9]. Moreover, Neitzel, (2016) expressed that the size of wires in any given circuit is based on the different cost factors, space considerations and on the expected amount of current under the normal operating conditions [8]. The high flow of current in wires and the low resistance of the circuit leads to the excessive heat within the circuit. The excessive high heat within wires can also cause the short in between other wires and can result in the explosion [9].

\subsubsection{Excessive Heat}

The excessive of heat is also one of the conditions in which protection devices are required. Ludwinek, Szczepanik and Sułowicz, (2017) mentioned that every issue or problem that is associated with the excessive current and direct short within electrical circuit directly concern the heat which is generated through higher current [10]. Excessive heat has different consequences such as; the possibility of hazardous fumes, damage to circuit components and the possibility of fire. Mitolo and Montazemi, (2014) claimed that excessive heat could occur without the excessive current or direct short. However, the practical example of excessive heat is the failure of the bearings on motor or generator which cause them to overheat [7]. Furthermore, Padilla et al. (2014) stated that excessive heat would be a problem if the overall temperature around any electrical or electronic circuit rise due to the failure of the cooling system [6]. Therefore, it can be stated that if excessive heat is present in any circuit, then there is the high possibility of damage, the existence of hazardous fumes and fire. The overall conditions that are mentioned in this sections have high potential danger. Therefore, different electrical or electronics engineers use different circuit protection devices to reduce the overall impact of all these conditions [10].

\subsection{Circuit Protection Devices}

Circuit protection devices have the large value in reducing the impact of hazardous conditions or in restricting the hazardous conditions from rising. These devices are also used for stopping the flow of current in the electric circuit therefore, these devices are called circuit protection devices. Expósito et al. (2016) mentioned that it is necessary to use these devices efficiently as these circuit protection devices are required to be connected in series with the specific protected circuit [4]. However, it is analyzed that the devices of circuit protection usually operates by opening or intruding the current within the circuit. The opening of protection devices is necessary for the electric circuit as it identifies the issues or problem within the circuit that are required to be resolved before the restoration of current. Franks, Williams, and Cole, (2014) stated that if any problem occurs within the electric circuit, engineers or circuit designers use the protection devices for the isolation of 
faulty circuit from the unaffected circuit [5]. These protection devices respond in time for protecting the different unaffected components in the faulty electric circuit. Gan, (2014) described that these devices should not be opened during the operation of the normal circuit [1]. As the technologies are getting improved, various devices are getting introduced, but the two major circuit protection devices; Fuses and Circuit breakers are analyzed in this section.

\subsubsection{Fuses}

In this study, the supplier performance is considered as the first Circuit protection devices are for the protection of electric circuit and fuse is referred as the simplest and efficient circuit protection devices. This protection device is usually used at the beginning of the circuit at which electricity is used. Zainal, (2017) stated that there is the large evolution of different electronic devices and components as old fuses are referred as a bare wire between two different connections [11]. However, the length of that wire within the fuse is smaller than the conductor that is placed inside the fuse. Ludwinek, Szczepanik, and Sułowicz, (2017) claimed that the wire of that old fuses usually melts before the conductor which was protected [10]. Moreover, it is observed that the recent or new fuses do not have the copper fuse link which was used as the fuse element inside the fuse. The copper fuse link is also known as the meeting part of the fuse. Therefore, other metals replaced it. Mitolo and Montazemi, (2014) stated that different tubes or enclosures were developed after the change of copper to other metals for holding the melting point [7]. Whereas, the arc that occurs after the melting of elements is also contained by the enclosed fuses which helped in the addition of different materials. However, these devices are used by most of the circuit designers to protect the devices and to restrict the different hazardous conditions from occurrence [9]. Figure 1 shows the utilization of wires within fuse to get the clearer concept.

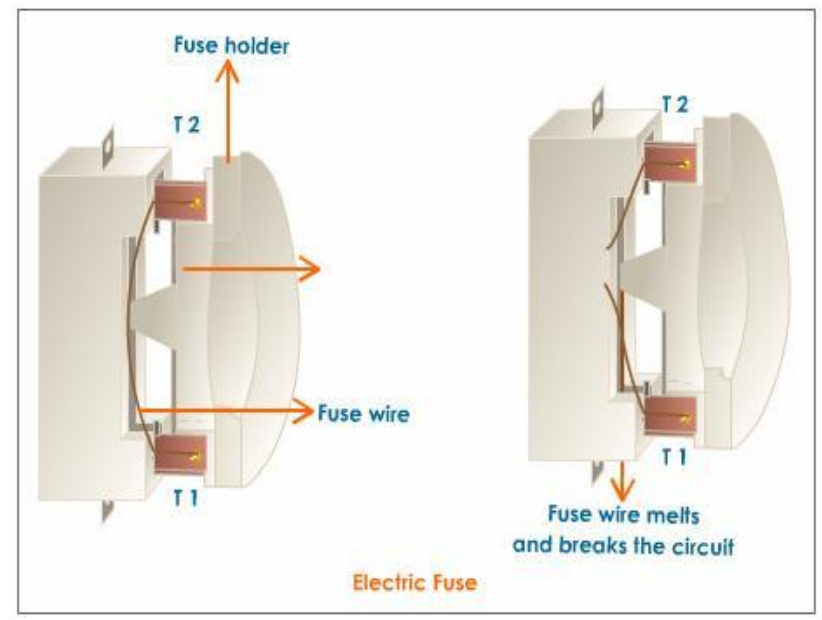

Fig 1: Fuse DiagramSource: (www.tutorvista.com)

\subsubsection{Circuit Breakers}

Circuit breakers are also an efficient circuit protection devices which have the more effective in protecting the electric circuit. Franks, Williams, and Cole, (2014) claimed that fuses are used for the protecting the electric circuits, but it can also be destroyed within the process of opening any circuit [5]. The problems of excessive heat or direct short of current within any electric circuit require the replacement of fuse in the circuit as these circuit protection devices can be used more than once only when it solves the problems of replacement fuses. These devices can be reused without replacement of parts as such devices are resettable, reliable and tamper-proof and are known as the circuit breakers. Circuit breakers are used for breaking (open) the circuit and help different circuit designers to manage the flow of current efficiently. Kageyama et al. (2015) identified that circuit breaker has the more preference than fuses as this circuit protection devices are used for the protection of electric circuits and can be used multiple times[3]. Figure 2 shows the sample of circuit breakers that are used in daily routing electrical appliances and also in industries.

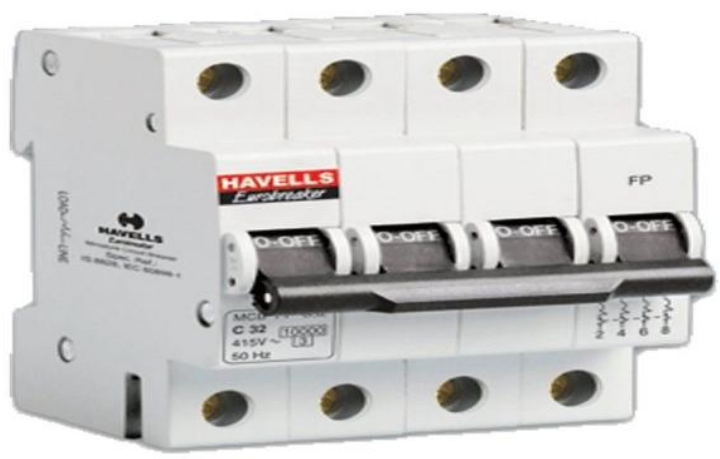

Fig 2: Sample of Circuit BreakerSource: (www.quora.com

\section{METHODOLOGY}

Research studies cover different method for undertaking the research more appropriately and efficiently such as qualitative and quantitative research method. Both these methods have different approaches and methods for collecting the overall information regarding the efficiency of electric circuit protection devices. The qualitative research method is known for analyzing the data through the understanding and perspectives of different theories and studies. Whereas, the other method is quantitative research method which covers the data analysis through the information collected by specific and selected participants. The research of electric circuit protection devices is undertaken through using the quantitative research method.

\subsection{Quantitative Research Method}

The research of electrical circuit protection devices is based on survey analysis for recognizing the impact of these devices on different industries and for finding the overall issues while designing the protection system. This research method covers a large number of participants as it has the large focus on identifying the proper and efficient values through the survey. It can be stated that there are various studies related to the electrical protection devices in which quantitative research method is used. Therefore, this research will try to identify the required information through quantitative research method [12]. Moreover, quantitative research method also helps the researcher in getting the more accurate and appropriate values of this research study.

\subsection{Data Collection Method}

Collection of data is the necessary step in every research, but this step covers two different methods such as; secondary data or primary data. It can be stated that both these methods have the large value in the research context as it helps research in exploring the research phenomenon and in analyzing a large amount of data. Secondary data is known as the result or identified outcomes of different studies. Smith, (2015) stated 
that secondary data is known as the collection of data from various theories and studies [12]. Furthermore, the other data collection method is primary data which is referred as the collection of data through analyzing the different concepts and perspectives of participants. This data collection tool has the large value as it provides the more effective and authentic data. Therefore, the research will use this method for collecting the data

\subsection{Sampling}

Sampling is referred as the technique of selecting the appropriate population for the research study. Smith, (2015) mentioned that sampling is referred as the selection of participants for collecting the data through specific data collection method [12]. The selected sampling for this survey is 70 different technicians and managers of different industries through which utilization of electrical circuit protection devices is analyzed. Furthermore, this research has the focus on identifying the appropriate and authentic facts and results, therefore, all the selected participants have the detailed knowledge about electrical circuit designing and troubleshooting.

\section{RESULTS AND ANALYSIS}

Table1. Statistics

\begin{tabular}{|c|c|c|c|c|c|}
\hline & $\begin{array}{c}\text { How } \\
\text { efficientl } \\
y \\
\text { electrical } \\
\text { circuit } \\
\text { protectio } \\
\text { n devices } \\
\text { are used } \\
\text { within } \\
\text { industries } \\
?\end{array}$ & 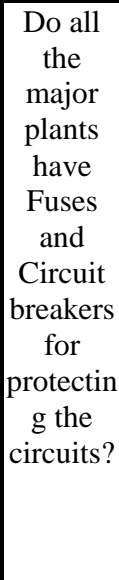 & $\begin{array}{c}\text { How much } \\
\text { these } \\
\text { electrical } \\
\text { circuit } \\
\text { protection } \\
\text { devices } \\
\text { have } \\
\text { helped } \\
\text { organizatio } \\
\text { n from the } \\
\text { occurrence } \\
\text { of different } \\
\text { hazardous } \\
\text { conditions? }\end{array}$ & $\begin{array}{l}\text { What are } \\
\text { the major } \\
\text { reasons } \\
\text { for } \\
\text { developin } \\
\mathrm{g} \text { the } \\
\text { protection } \\
\text { system in } \\
\text { the } \\
\text { different } \\
\text { electrical } \\
\text { circuit? }\end{array}$ & \begin{tabular}{|c} 
Do \\
hazardou \\
$\mathrm{s}$ \\
condition \\
s occur \\
due to \\
lack of \\
utilizatio \\
$\mathrm{n}$ or \\
efficienc \\
y of \\
electrical \\
circuit \\
protectio \\
$\mathrm{n}$ \\
devices?
\end{tabular} \\
\hline $\begin{array}{c}\text { Valid } \\
\mathrm{N}_{\text {Missin }} \\
\mathrm{g}\end{array}$ & 70 & 70 & 70 & 70 & 70 \\
\hline
\end{tabular}

The table of statistics shows that all the questions are responded by the participants appropriately as the answer ratio of every question is 70 and there is no missing answer in the result. The survey covers the five different questions for identifying the importance of electrical circuit protection devices in the industries. The result of every individual question is described below.
Table2. How efficiently electrical circuit protection devices are used within industries?

\begin{tabular}{|r|c|c|c|c|}
\hline & $\begin{array}{c}\text { Freque } \\
\text { ncy }\end{array}$ & Percent & $\begin{array}{c}\text { Valid } \\
\text { Percent }\end{array}$ & $\begin{array}{c}\text { Cumulative } \\
\text { Percent }\end{array}$ \\
\hline $\begin{array}{c}\text { Extremely } \\
\text { efficient }\end{array}$ & 18 & 25.7 & 25.7 & 25.7 \\
Very efficient & 32 & 45.7 & 45.7 & 71.4 \\
Valid $\begin{array}{c}\text { quite efficient } \\
\text { somewhat }\end{array}$ & 8 & 11.4 & 11.4 & 82.9 \\
important & 3 & 4.3 & 4.3 & 87.1 \\
inefficient & 9 & 12.9 & 12.9 & 100.0 \\
Total & 70 & 100.0 & 100.0 & \\
\hline
\end{tabular}

The first question is about the efficient utilization of electrical circuit protection devices in the industries which shows the positive result of this question. It can be analyzed that maximum of the participants were in favor of high utilization of these devices whereas, some ratio of participants refused to use these devices. It can be stated by analyzing the result of the first question that industries have the large utilization of electric circuit protection devices. Furthermore, the result is also justified by the following graph.

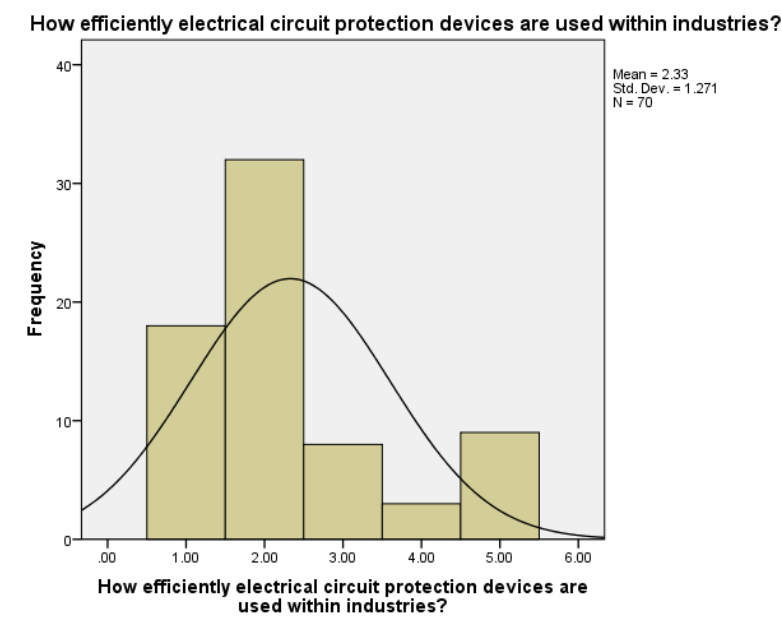

Fig 3: Utilization of protection devices by Industry

Table3. Do all the major plants have Fuses and Circuit breakers for protecting the circuits?

\begin{tabular}{|rc|c|c|c|c|}
\hline & Frequency & Percent & $\begin{array}{c}\text { Valid } \\
\text { Percent }\end{array}$ & $\begin{array}{c}\text { Cumulative } \\
\text { Percent }\end{array}$ \\
\hline Yes & 54 & 77.1 & 77.1 & 77.1 \\
Valid No & 16 & 22.9 & 22.9 & 100.0 \\
& Total & 70 & 100.0 & 100.0 & \\
\hline
\end{tabular}

The other question is for identifying the usage of fused and circuit breaker for the protection of electric circuit at major plants of industries. The result of this question is also positive as more than $75 \%$ participants responded positively. Therefore, it is identified from this question that all major plants use the protection devices of Fuses and Circuit breakers 
for the protection of their circuit.

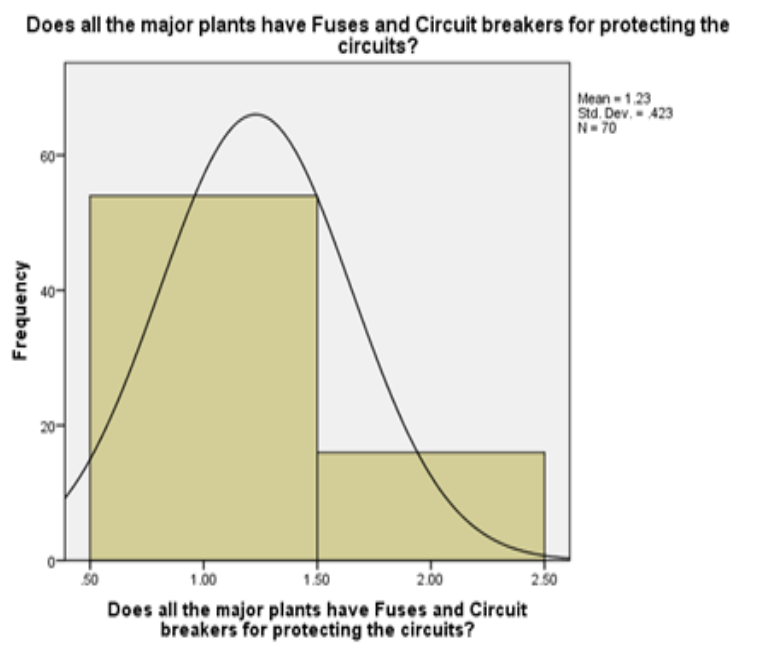

Fig 4: Fuses and breakers for Protection Devices

Table4. How much these electrical circuit protection devices have helped organization from the occurrence of different hazardous conditions?

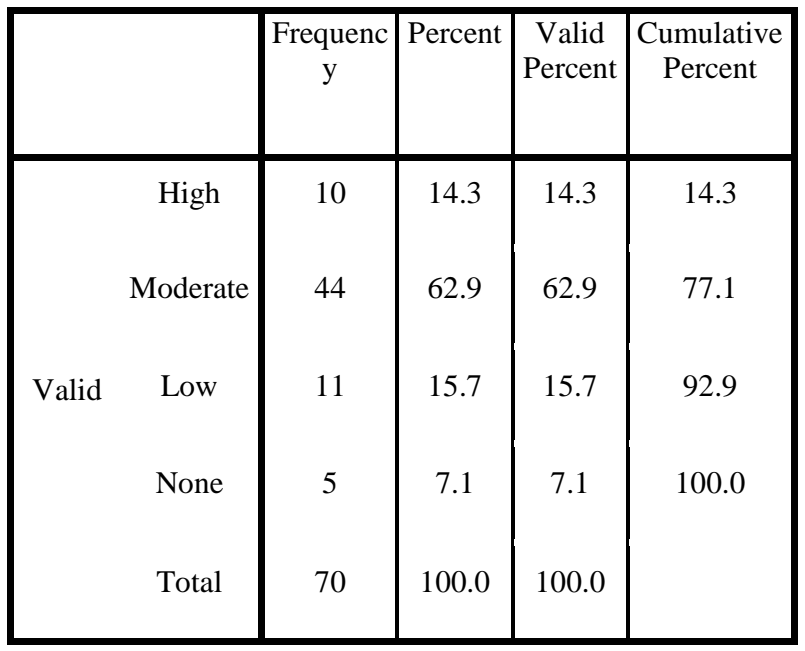

The third question is about the impact over-occurrence of hazardous conditions due to the utilization of electrical circuit protection devices. The results from the above table show that more than $75 \%$ respondents agreed that utilization of these devices reduces the occurrence of hazardous conditions in different electrical circuits. There were some opposite responses as well, but the overall response of this question shows that utilization of electric circuit protection reduces the occurrence of hazardous conditions.

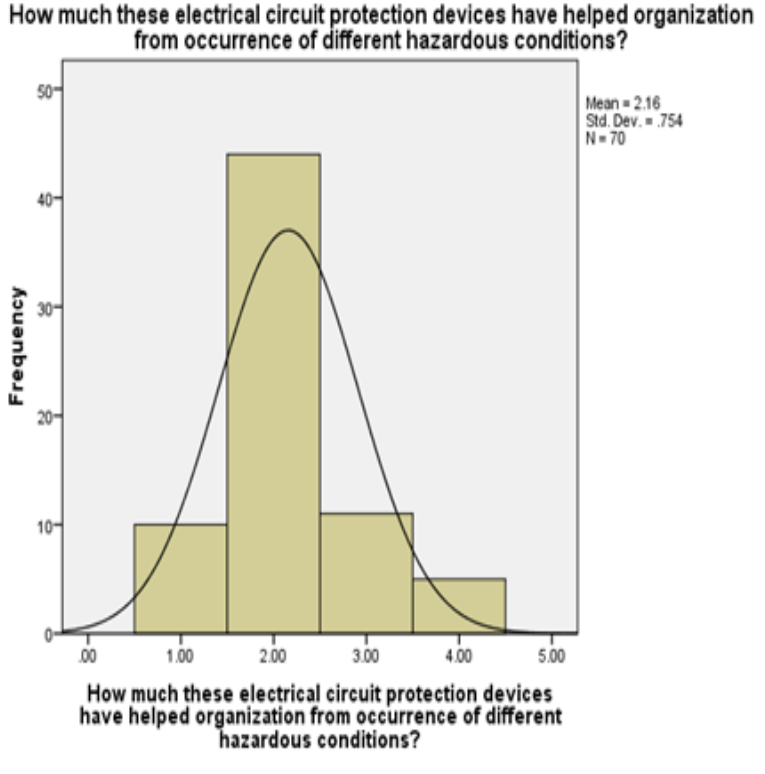

Fig 5: Protection Devices and Hazardous Conditions

Table5. What are the major reasons for developing the protection system in the different electrical circuit?

\begin{tabular}{|c|c|c|c|c|}
\hline & Frequency & Percent & $\begin{array}{c}\text { Valid } \\
\text { Percent }\end{array}$ & $\begin{array}{c}\text { Cumulative } \\
\text { Percent }\end{array}$ \\
\hline $\begin{array}{c}\text { Failure of } \\
\text { circuits } \\
\text { lack of } \\
\text { efficiency } \\
\text { in circuit }\end{array}$ & 13 & 18.6 & 18.6 & 18.6 \\
Valid $\begin{array}{c}\text { increasing } \\
\text { rate of } \\
\text { hazardous } \\
\text { conditions }\end{array}$ & 38 & 54.3 & 54.3 & 100.0 \\
Total & 70 & 100.0 & 100.0 & 45.7 \\
\hline
\end{tabular}

The fourth question is about identifying the major reasons for the development of protection system in the different electrical circuit. The result shows that most of the industries develop protection system for the increased rate of hazardous conditions. Furthermore, lack of efficiency is the second most chosen option for the development of protection system within electrical circuits. Some respondents also responded in favor of the first option which is the failure of circuits. 
What are the major reasons for developing the protection system in different

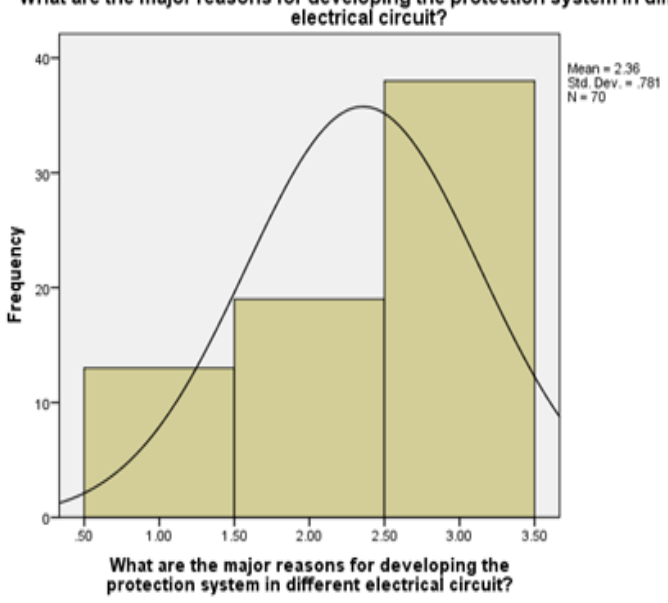

Fig 6: Reasons for Developing Protection devices

Table6. Do hazardous conditions occurs due to lack of utilization or efficiency of electrical circuit protection devices?

\begin{tabular}{|r|c|c|c|c|}
\hline & Frequency & Percent & $\begin{array}{c}\text { Valid } \\
\text { Percent }\end{array}$ & $\begin{array}{c}\text { Cumulative } \\
\text { Percent }\end{array}$ \\
\hline Yes & 61 & 87.1 & 87.1 & 87.1 \\
Valid No & 9 & 12.9 & 12.9 & 100.0 \\
Total & 70 & 100.0 & 100.0 & \\
\hline
\end{tabular}

The last question is about the efficient use of electrical circuit protection devices against hazardous conditions. The table shows $87 \%$ respondent answered positively for this question. Therefore, it can be analyzed that hazardous conditions are due to the effectiveness of protection devices. Furthermore, it is identified that maximum of the respondent answered positively that increase in the hazardous conditions is due to lack of efficient utilization of electrical circuit protection devices.

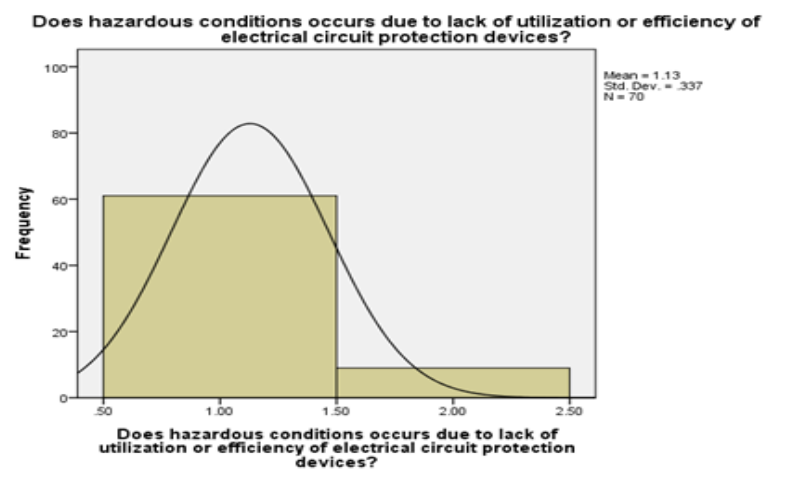

Fig 7: Effect of Hazardous Conditions

\section{CONCLUSION}

Electric circuit protection devices are the most effective devices which are used for the protection of different circuits. The research identified that all these instruments have the large value for the protection of electrical circuits. Different industries use the devices for reducing the overall ratio of occurrence of hazardous conditions. It is also identified that most industries used circuit breakers and fuses as the electrical circuit protection devices for protecting their circuits from different hazardous conditions.

\section{REFERENCES}

[1] Gan, N. P. (2014). U.S. Patent No. 8,681,469. Washington, DC: U.S. Patent and Trademark Office.

[2] Dougherty, J. J. (2015). U.S. Patent Application No. $14 / 713,725$.

[3] Kageyama, R., Takeda, T., Murano, K., \& Itagaki, T. (2015). U.S. Patent Application No. 14/969,275.

[4] Expósito, A. G., Gomez-Exposito, A., Conejo, A. J., \& Canizares, C. (Eds.). (2016). Electric energy systems: analysis and operation. CRC Press.

[5] Franks, J. L., Williams, S. E., \& Cole, R. (2014). U.S. Patent No. 8,681,463. Washington, DC: U.S. Patent and Trademark Office.

[6] Padilla, M., Michl, B., Thaidigsmann, B., Warta, W., \& Schubert, M. C. (2014). Short-circuit current density mapping for solar cells. Solar Energy Materials and Solar Cells, 120, 282-288.

[7] Mitolo, M., \& Montazemi, P. (2014, February). Electrical safety in the industrial workplace: An IEC point of view. In Electrical Safety Workshop (ESW), 2014 IEEE IAS (pp. 1-8). IEEE.

[8] Neitzel, D. K. (2016, June). Electrical safety by design and maintenance. In Pulp, Paper \& Forest Industries Conference (PPFIC), 2016 IEEE (pp. 6-13). IEEE.

[9] Xin, L., Xiong, V., \& Li, B. (2014, October). Analysis of backup protection of fuse and circuit breaker. In Lightning Protection (ICLP), 2014 International Conference o (pp. 1878-1883). IEEE.

[10] Ludwinek, K., Szczepanik, J., \& Sułowicz, M. (2017). Experimental analysis of assessing of the tripping effectiveness of miniature circuit breakers in an electrical installation fed from a synchronous generator set. Electric Power Systems Research, 142, 341-350

[11] Zainal, Z. (2017). Case study as a research method. Jurnal Kemanusiaan, 5(1)

[12] Smith, J. A. (Ed.). (2015). Qualitative psychology: A practical guide to research methods. Sage. 